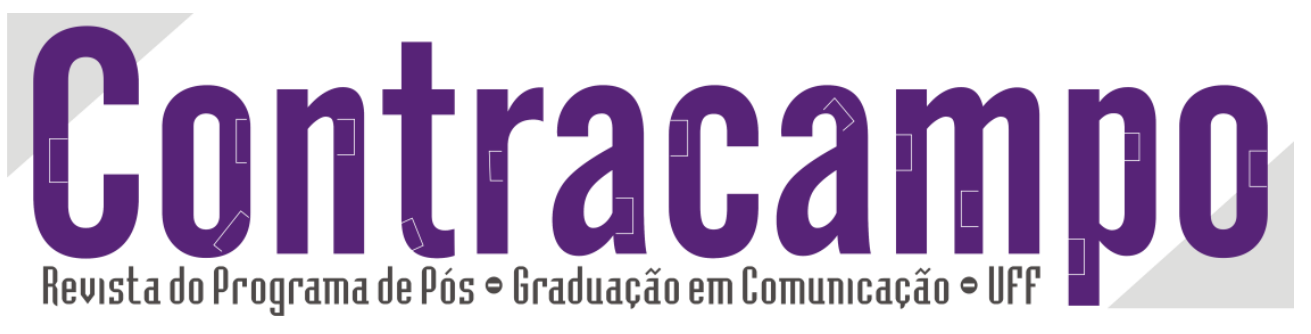

\title{
Quando o cinema é a maior sofisticação: experiências sensíveis, desejo e práticas de consumo nas salas exibidoras de luxo do Rio de Janeiro
}

\author{
When the film is more sophisticated: \\ sensory experiences, desire and consumption practices \\ in the luxury picture theaters of Rio de Janeiro
}

Talitha Ferraz talitha.ferraz@gmail.com Doutoranda da Escola de Comunicação da UFRJ (ECO-UFRJ), membro da Coordenação Interdisciplinar de Estudos Contemporâneos (CIEC-UFRJ), prof. do depto. de Jornalismo da Universidade Estácio de Sá, Coordenadora de Telejornalismo do Núcleo de Comunicação da Unesa-Madureira (Nucom).

Lúcia Santa Cruz

luciasantacruz@gmail.com

Doutora em Comunicação e Cultura (UFRJ), professora do curso de jornalismo da ESPM/RJ, pesquisadora da Coordenação Interdisciplinar de Estudos Contemporâneos (CIEC-UFRJ).

Ao citar este artigo, utilize a seguinte referência bibliográfica

FERRAZ, Talitha; CRUZ, Lúcia Santa. Quando o cinema é a maior sofisticação: experiências sensíveis, desejo e práticas de consumo nas salas exibidoras de luxo do Rio de Janeiro. In: Revista Contracampo, v. 24, n. 1, ed. julho, ano 2012. Niterói: Contracampo, 2012. Pags: 249-265.

Enviado em: 15 de mar. de 2012 Aceito em: 16 de jul. De 2012

\section{PPG COM $=$ UFF}

\section{Edição 24/2012}

Temáticas diversas

Contracampo

Niterói (RJ), v. 24, n. 1, jul./2012.

e-ISSN 2238-2577

A Revista Contracampo é uma revista eletrônica do Programa de PósGraduação em Comunicação da Universidade Federal Fluminense e tem como objetivo contribuir para a reflexão crítica em torno do campo midiático, atuando como espaço de circulação da pesquisa e do pensamento acadêmico. 


\section{Resumo}

Este trabalho aborda as construções de sociabilidade envolvidas nas práticas de espectação cinematográfica em cinemas de luxo cariocas. Examinamos como se dão as formas de consumo realizadas pelos frequentadores de dois cinemas do Rio de Janeiro, que seguem o perfil prime. Partindo de uma abordagem histórica acerca do cenário exibidor da cidade, investigamos os modos de inserção dos indivíduos e as construções de sociabilidade efetivadas nesses espaços, buscando compreender os aspectos simbólicos envolvidos nessas experiências de lazer.

Palavras-chave: Cinema de luxo (Rio de Janeiro); Espectação cinematográfica; Consumo.

\section{Abstract}

This paper discusses the construction of sociability practices involved in cinematographic attendance at Rio luxury theaters. We examine the way patrons of two prime cinemas in Rio de Janeiro arrange their consumption forms. From a historical perspective about the city film exhibition scene, we investigate the modes of inclusion of individuals and also the sociability that arises from these spaces, trying to understand the symbolic aspects involved in such leisure experiences.

Keywords: Luxury theaters (Rio de Janeiro); Cinematographic attendance; Consumption. 
I novações e buscas por modificações nos padrões de exibição e arranjos espaciais das salas de cinema parecem ser movimentos comuns do mercado cinematográfico desde os primórdios desta indústria, no que concerne ao braço exibidor. Os cinemas, como equipamentos coletivos urbanos de lazer (FERRAZ, 2009), isto é, edificações voltadas para a vidência de filmes e práticas de sociabilidade, passam há mais de um século por elaborações e reelaborações de padrões associados aos perfis de público e a fatores como disponibilidade de locais para a construção de salas no espaço citadino (o que se liga à localização do lazer nas cidades), condições de acessibilidade do público, apostas comerciais do mercado e tipos de produções fílmicas a serem assistidas.

Diante destas relações, as quais se não ditam a forma com a qual os cinemas se apresentam em nossas ruas e shopping centers, pelo menos ajudam a configurar suas faces, acreditamos haver um componente importante nos agenciamentos entre as espacialidades e os perfis de salas exibidoras e os modos de participação que as pessoas (enquanto espectadoras/ frequentadoras/ consumidores) efetivam nesses locais do entretenimento: a ordem do desejo, inserida nas produções de subjetividade, que constituem a experiência e, no caso de nosso estudo, as práticas de consumo envolvidas na atividade de ida ao cinema.

Aqui buscaremos investigar - com o auxílio de um exame de traços históricos da exibição cinematográfica no Rio de Janeiro e de uma pesquisa etnográfica - as possíveis relações entre as concepções acerca das fontes do prazer e das experiências da ordem do sensível e das emoções - trabalhando o âmbito do desejo e das subjetividades fabricadas e realizadas em certos espaços na contemporaneidade - e a frequentação das salas de cinema cariocas qualificadas como "prime" ou "de luxo", isto é, locais voltados para a exibição comercial de filmes, que apostam em conforto (como poltronas namoradeiras tipo chaise, hall de espera no estilo lounge, entrada privativa) e serviços adicionais diferenciados (como cardápios assinados por chefes de cozinha, cartas de vinho e espumantes, e garçons que servem o espectador em seus assentos). 
Para cada época, um cinema, uma tecnologia e um tipo de espectação

No Brasil, mais especificamente na cidade do Rio de Janeiro, o modelo de sala de cinema acompanhou em alguma medida "a troca da casa pela rua" (GONZAGA, 1996: 30), quando no final do século XIX a urbanização da então capital fez surgir espaços de convivência e encontros entre a população inspirada pelo espírito civilizatório "smart e chic" (Idem). Era o tempo dos cinematógrafos e casas ao estilo vaudeville exibidoras de fitas, cujos atrativos eram ajudados pela curiosidade das pessoas pela tecnologia da projeção de imagens em movimento.

Aliadas a demais divertimentos como esquetes de mágica, concertos, exposições de bonecos de cera etc, as projeções cinematográficas aconteciam em espaços circunstanciais e provisórios, a exemplo de salões como o Salão de Novidades Paris no Rio (localizado na Rua do Ouvidor), parques e teatros (GONZAGA, 1996; ARAÚJO, 1976).

Entre 1907 e 1911, foram abertos cerca de 100 cinemas na cidade, e os primeiros circuitos exibidores se estabeleceram de ponto a ponto apoiando-se com mais força em localidades como Centro (com destaque para a Avenida Central), subúrbios da Central do Brasil e da Leopoldina, e Zona Norte (com destaque para a Tijuca) - atingindo em menor escala alguns bairros da Zona Sul. Caracterizavam-se em grande medida pelo sincronismo entre as imagens das fitas e o áudio de gramofones, pianos ou músicas apresentadas por cantores-atores. Assim se estabeleceu o primeiro circuito de cineteatros do Rio, que entrou em crise em 1911 e só se revigorou por volta de 1920.

O circuito voltaria a crescer, só que mais lentamente. Por volta de 1920 contavam-se cerca de 70 salas em funcionamento na cidade. Esta seria uma base mais duradora, pois muitos desses cinemas permaneceriam abertos por décadas. Dos remanescentes do circuito original, uma parte atrelou-se de 1910 em diante à estratégia de palco e tela (GONZAGA, 1996: 98).

Algumas características do mercado exibidor passaram a se modificar quando as companhias americanas, com seus métodos comerciais de distribuição, se consolidaram em território brasileiro. Apareceram fitas de filmes americanos com maior duração, o que exigiu transformações na estrutura das salas de cinema (tal como arejamento, limpeza), para proporcionar o mínimo de conforto aos espectadores que ficariam sentados por muito mais tempo em frente às telas. Grandes "elefantes brancos" 
(Capitólio, Glória, Rialto, Odeon, entre outros), prédios monumentais voltados para exibição cinematográfica, começaram a despontar na década de 1920, dando o tom de "cidade dos cinemas" à área da Cinelândia, projetada por Francisco Serrador para a Praça Floriano, Centro do Rio. Apesar de um sucesso parcial, os cinemas da região enfrentaram uma precoce derrocada no início dos anos 1930 (GONZAGA, 1996).

Já na década de 1940, foi vez dos movie palaces se colocarem no cenário urbano como opções de lazer cinematográfico. Luxuosos e imponentes - dotados de salas de espera aconchegantes e bombonières bem servidas, lanterninhas alinhados, comodoros que recepcionavam os frequentadores na entrada, mobiliário e interiores trabalhados em detalhes de mármores e veludos, com poltronas acolchoadas e ar refrigerado - muitos tinham fachadas ao estilo art-déco. Este padrão de cinema tornou-se ideal para receber o movietone, já que o filme sonoro precisava de uma arquitetura que privilegiasse o tratamento acústico do espaço.

O ritual de ida ao cinema passava agora pela sensação de experimentar um ambiente de luxo e sofisticação, requinte e conforto de "sonhos aveludados" (VIEIRA e PEREIRA, 1982). Os autores João Luiz Vieira e Margareth Pereira (1982) dedicam esta mudança de perspectiva da sala de cinema à chegada do padrão Metro-Goldwyn-Mayer ao Rio de Janeiro. Ao lado de Metro Passeio, Metro-Tijuca, Metro-Copacabana, outros cinemas como Carioca, São Luiz, Roxy, Miramar, Imperator e Olaria, por exemplo, fizeram parte de uma geração, na qual a mentalidade envolvida nas práticas de lazer cinematográfico tinha como importante veia a tendência à sofisticação e valorização de aspectos sensórios dos espectadores (tato, visão, audição, sensação de frescor via refrigeração).

No Rio de Janeiro, a cadeia de cinemas que a Metro-Goldwyn-Mayer fez construir para exibir as suas produções com exclusividade, fez com que o comércio cinematográfico sofresse um forte impacto e que, junto ao público, se estabelecessem padrões e necessidades novos que reforçavam não apenas a reprodução continuada dos seus filmes como também consagrasse uma vez mais a noção já cristalizada de que cinema americano era o verdadeiro Cinema. (...) Ao controlar seus próprios cinemas, a MGM deu um novo passo no sentido de dominar todas as etapas da indústria cinematográfica (...) (VIEIRA e PEREIRA, 1982: 29).

Percebe-se com isso que, já em meados do século XX, a aposta dos exibidores em luxo e conforto, e sua relação direta com satisfação/ elaboração de desejos dos espectadores durante a prática de lazer cinematográfico, não parece ser uma 
prerrogativa das salas de cinema do tipo prime que despontam no cenário carioca (e em demais metrópoles brasileiras) na contemporaneidade.

Com o tempo, as dinâmicas relacionadas à localização urbana do lazer, às edificações dos cinemas, aos tipos de produção fílmica exibida e à atividade de espectação cinematográfica em si conferiram à sala exibidora novos aspectos. Outros padrões, a exemplo dos cinemas mais compactos localizados em galerias, apareceram no mercado de exibição. Tais modificações, assim como o desaparecimento dos movie palaces e dos cinemas mais modestos (poeirinhas) das ruas e praças, parecem guardar ligações com as transformações do cenário urbano (aceleradas nos anos JK), como especulação imobiliária e necessidade de haver estacionamentos próximos aos locais de entretenimento por causa da extrema motorização da cidade. A década de 1960 trouxe tabelamentos dos preços dos bilhetes no Brasil, crise em Hollywood, sedimentação da TV no mundo (e mais tarde, em nosso país), ascensão da indústria de "filmes de arte" e europeus etc, que atingiram direta e indiretamente os circuitos exibidores e os arranjos técnicos e arquitetônicos da sala de cinema.

A era dos shopping centers, que começa a partir de 1975 no Rio de Janeiro com a inauguração do Shopping da Gávea ${ }^{1}$, marcou um novo lugar para a ida ao cinema na cidade. Associados ao fenômeno do videocassete, com suas sessões domésticas, os movimentos de espectação elitizaram-se no final dos anos 1970 e durante as décadas de 1980 e 1990. Assistir a filmes tornou-se, em grande medida, uma atividade realizada em núcleos apartados da rua e demais áreas públicas.

O hábito de ver filmes também se transferiria quase que inteiramente para o ambiente doméstico. As consequências não poderiam deixar de ser uma extinção progressiva dos cinemas populares e um encolhimento do setor (...). A lógica do processo, entretanto, era outra. Como as bilheterias não mostraram sinais de recuperação aos níveis da época de ouro, enveredou-se pelo caminho da elitização do lazer cinematográfico, garantindo-se um consumidor mais fiel (GONZAGA, 1996: 245).

\footnotetext{
${ }^{1}$ No Rio de Janeiro, os primeiros shopping centers foram o Shopping da Gávea, aberto em 1975, e o Cassino Atlântico, fundado em 1979 (que se caracterizavam mais como centros de compras semifechados do que como shopping center propriamente dito). Logo em seguida, surgiu o Rio Sul, em 1980, e o Barra Shopping, em 1981, que efetiva de vez a reprodução de uma cidade, com a oferta de serviços, lazer e opções de consumo, em seu interior cercado e isolado espacialmente das áreas de fato públicas da urbe.
} 
Apostando em um tipo de privatismo espacial, os centros de compras e lazer contemporâneos, isto é, os shopping centeres, oferecem serviços pautados pela segurança, garantia de estacionamento e diferenciação do público (com a manutenção muitas vezes de um status quo que exclui as camadas pobres e miseráveis destes ambientes). E foi neles que a sala de cinema encontrou mais um destino.

Nos últimos anos, a expansão do circuito exibidor brasileiro esteve estritamente relacionada ao crescimento dos shopping centers. Os dois setores se modernizaram e foram alvos de investimentos estrangeiros que contribuíram para estabelecer um novo padrão para o consumidor (ALMEIDA e BUTCHER, 2008, p.1).

Diante de alguns cinemas de rua remanescentes (salas de circuitos "alternativos" que surgiram nos anos 1980, 1990 e início do século XXI, como o Grupo Estação, por exemplo, que apostou inicialmente no bairro de Botafogo), a sala de exibição comercial ganhou novas feições quando os modelos multiplex (geralmente complexos que têm entre 5, 8, até 14 salas de exibição) e megaplex (com mais de 15 salas) aportaram em solo carioca entre a década de 1990 e os dias atuais. Geralmente, na solução encontrada pelo setor exibidor, esses conjuntos de salas são alocados dentro de shopping centers.

Acreditamos haver neste caso uma reconfiguração tanto da estrutura e localização das salas, como dos rituais de espectação cinematográfica que contam agora com novas tecnologias de exibição (som e imagem), de serviços (terminais de autoatendimento para compra de ingressos) e aparatos que dão novo rosto a elementos constitutivos dos cinemas, tais como as telas de plasma que anunciam as atrações e horários em vez dos tradicionais cartazes, letreiros e displays de papelão. Além disso, a falta de arquitetura própria (já que a maioria se insere dentro de shopping centers) e a aposta ao máximo em conforto, como, por exemplo, o proporcionado pelas poltronas acolchoadas, namoradeiras e as mais recentes chaises, redimensionam a estrutura dos equipamentos de exibição, agora dotados do perfil multiplex. Ferraz aponta a possibilidade do 
(...) multiplex [se constituir como] um "meio exigente" (CAIAFA, 2008:2), ou seja, um ambiente que impõe aos usuários objetos tecnológicos, componentes que demandam um tipo de knowhow, determinados comportamentos e posturas para seu uso e consumo (FERRAZ, 2009: 277).

Nesta perspectiva de instância que propõe novos agenciamentos na forma de fruição do cinema, os complexos multiplex instalam no Brasil, a partir do final da primeira década deste século, salas de cinema qualificadas como "prime" ou "de luxo", isto é, locais voltados para a exibição comercial de filmes, que apostam em conforto e serviços adicionais diferenciados, não disponíveis nas demais salas.

\section{Cinema: a maior sofisticação}

No Rio de Janeiro, as salas de luxo localizam-se no multiplex UCI do New York City Center (centro de lazer e compras anexo ao Barra Shopping), cujas salas 8 e 9 recebem o nome De Lux, e no shopping Rio Design Barra, que, entre suas três salas de cinema, oferece ao público um espaço nomeado VIP. Ambos os exemplos estão presentes no bairro da Barra da Tijuca, na Zona Oeste do Rio de Janeiro, ocupado em grande escala por pessoas das classes média e alta cariocas ${ }^{2}$. As salas diferenciadas, voltadas a princípio para uma frequentação que envolve um consumo sofisticado e o oferecimento de novos itens na composição do equipamento de lazer cinema, não são novidade no Brasil, nem no mundo. Em terras brasileiras, esse perfil de cinema foi instalado pela primeira vez na cidade de São Paulo. Brasília é outra praça que detém cinemas de luxo.

O Rio de Janeiro ganhou seu primeiro cinema prime em janeiro de 2011, quando o foi inaugurada a sala Vip do Rio Design Barra, com 58 lugares. Em novembro de 2011, a rede UCI usou parte da estrutura de seu amplo complexo no New York City Center para construir um espaço totalmente reservado e dedicado à experiência de espectação como artigo de luxo ${ }^{3}$. As salas De Lux do UCI oferecem mimos aos consumidores/espectadores e comportam 180 assentos, sete centímetros mais largos do que os usuais, com duas configurações, segundo aponta reportagem da revista Veja Rio.

\footnotetext{
${ }^{2}$ Até maio, o bairro deve ganhar mais uma sala, administrada pela rede Cinemark, em um shopping em construção, qualificado como de luxo.

${ }^{3} \mathrm{O}$ apelo utilizado pelo UCI é "Permita-se viver um momento exclusivo. Cinema com conforto e sofisticação".
} 
A primeira, instalada mais próximo da tela, é do tipo chaise longue, com regulagem na altura do encosto para a cabeça. A segunda, localizada na parte posterior, tem a inclinação do suporte para as pernas e do encosto variável, chegando a quase 180 graus. (...) A conta do programa, como seria de imaginar, costuma ser salgada. Um casal que decida ver um filme e pedir duas minigarrafas de espumante nacional Chandon e pipoca aromatizada com azeite trufado gastará cerca de 150 reais. Para oferecer tantos agrados a seus clientes, a rede americana UCI, a responsável pelas salas, investiu 2,5 milhões de reais nas novas instalações. Com dezesseis complexos espalhados por oito cidades brasileiras, a exibidora escolheu o mercado carioca para estrear a novidade (KNOPLECH, 2011).

Por meio de uma pesquisa etnográfica realizada no De Lux UCI em janeiro deste ano, percebemos que a estratégia de diferenciação do serviço do cinema aposta na criação de um espaço onde as sensações provocadas pelo ato de consumo de artefatos de luxo (ou mais qualificados, seja pela raridade no cotidiano de classes médias e baixas pipoca com azeite trufado, espumantes e águas importadas - ou pelo preço) ultrapassam o que deveria ser, de fato, a função do equipamento, isto é, a exibição cinematográfica.

A começar pela bilheteria especial, que fica na entrada do UCI separada da bilheteria das outras salas, passando pela configuração da sala de espera (decorada ao estilo lounge, com mesinhas e sofás de couro, iluminação indireta, rede de internet Wi-fi liberada, e garçons que oferecem o cardápio), notamos que o De Lux se propõe à fabricação de desejos, emoções e sensações que, se não complementam, entorpecem a prática de espectação, seguindo uma temática de requinte alinhada a um fetichismo da sofisticação.

Entre os depoimentos coletados entre alguns frequïentadores do local, elementos como conforto e exclusividade, decoração, experiências diferenciadas e de luxo e atendimento especial são os fatores de atração dessas salas

Gosto muito de cinema e vou toda semana. Acho bacana essa experiência daqui porque o UCI dá outra oportunidade para o espectador, seja na sala IMAX, mais voltada para a tecnologia, seja na De LUX, onde eu posso relaxar. Vou assistir ao Sherlock Holmes e até já vi antes, mas quero ver como é assisti-lo aqui. O diferencial é o atendimento, o conforto, é mais tranquilo para comprar, tem guichê preferencial (Maria Isabel, publicitária, 22 anos).

$\mathrm{O}$ atendimento é diferenciado e muito mais atencioso. O espaço e o conforto das poltronas é algo que realmente me faz pensar que mesmo sendo mais caro vale mais a pena e a arrumação das poltronas reduz o número de pessoas por sala. Dá uma sensação de satisfação por ter 
valido a pena o dinheiro gasto no ingresso (Bernardo, professor, 21 anos).

Para mim a grande diferença nem foi a sala de exibição em si, que claro, é mais confortável, mas o hall de espera me impressionou bem mais. Muito mais confortável, com serviço de atendimento diferenciado, cardápio especial e mais caro, claro. Banheiros mais limpos e espaçosos. Diferente ao extremo não, mas me senti mais relaxada. (Claudia, jornalista, 35 anos).

Pra mim, o principal de uma sala de luxo é o atendimento diferenciado. Isso vai desde a compra de ingresso, passando pelo serviço de bar, até o conforto. Tenho que ter acesso fácil, sala de espera confortável, bar com opções diferentes de comidas e bebidas. $\mathrm{O}$ serviço de garçom também é uma boa. Tudo isso é garantido, só a entrada exclusiva que eles anunciam na verdade é errada. Apesar de uma sala de espera confortável, ao contrário do que a propaganda sugere, a entrada é no mesmo local das outras salas. Em dia de cinema cheio isso pode complicar (Otávio, gestor de mídias sociais, 33 anos).

Uma mãe e uma filha, Fernanda e Milena, que estavam no UCI De Lux pela primeira vez, mas que já tinham frequentado cinemas prime em São Paulo, destacam pontos negativos no atendimento:

O que diferencia aqui é o público que é mais seleto, não tem falta de educação, celular tocando ou pessoas falando durante o filme, mas deixa a desejar no sentido de conforto. $\mathrm{O}$ atendimento é fraco, o banheiro está sujo. A conversa alta entre os funcionários também atrapalha. Quando você se dispõe a oferecer um serviço deste, deve haver um controle de tudo, até da disciplina dos funcionários. Pagamos meia, mas se fosse para pagar $\mathrm{R} \$ 86$ mais o consumo aqui dentro, o retorno em qualidade teria que ser melhor (Fernanda, exfuncionária de aviação).

Sobre o consumo dos itens do cardápio, nem todos os nossos interlocutores compraram pipoca especial ou espumantes, mas há quem tenha adquirido esses produtos. Mônica, que estava saindo às pressas de uma sessão, relata:

Não consumi nada, até porque eu vim parar aqui por acaso. Procurei o filme que queria legendado e aí só achei aqui. Quando vi o preço mais caro estranhei, mas assisti aqui mesmo. Todo mundo gosta de mordomia. Acho que vale a pena o custo.

Já o gestor de mídias sociais, Otávio, de 33 anos, comenta:

Consumi porque acho que faz parte do programa. Pipoca com azeite virou até uma mania em casa. Espumante podia estar mais gelado, ele estava apenas fresco. Eu adoro cinema, e pra mim este é um excelente programa. Adoro esse tipo de programa especial, e se for bem 
atendido não me incomodo de pagar mais por isso. É uma sensação de conforto, e de estar curtindo mais que o normal uma ida ao cinema.

Notamos que a descrição de emoções experimentadas é recorrente em praticamente todos os depoimentos de pessoas que já estiveram no UCI De Lux. Em vários depoimentos encontramos também com frequência o substantivo consumo ou o verbo consumir, indicando que parece haver para o espectador do cinema uma associação bem clara entre o ato de consumir em si e a sensação de sua experiência ao assistir a um filme em uma sala.

Se pensarmos o consumo como um sistema de comunicação (DOUGLAS e ISHERWOOD, 2009), desempenhando um papel central como estruturador de valores que constroem identidades, regulam relações sociais e definem mapas culturais, podemos concordar com Appadurai, quando este afirma que o consumo não é algo privado, atomizado e passivo, mas sim eminentemente social, correlativo e ativo (APPADURAI, 2008). Consumir é participar de um cenário de disputas por aquilo que a sociedade produz e pelos meios de usá-lo (CANCLINI, 2005).

Nossa proposta ao investigar a experiência de uso dos cinemas de luxo é de tomarmos o consumo desde sua condição estruturante, como dinâmica sensível e formatadora de uma ampla cultura comunicacional. Na perspectiva que o consumo é uma apropriação de códigos de pertencimento, entendemos, como Canclini, que consumo é sistema de significação, sendo que a verdadeira necessidade que supre é simbólica. "No consumo se constrói parte da racionalidade integrativa e comunicativa de uma sociedade" (CANCLINI, 2005:53). Por isso, assumimos uma perspectiva teórica que concebe o consumo como privilegiado campo de constituição da subjetividade na atualidade e se apoia no entendimento que todo consumo é cultural, sendo central no processo de reprodução social de qualquer sociedade (BARBOSA, 2006; CASTRO, 2006).

Numa concepção crítica, é possível encontrar autores como Gorz, para quem foi preciso criar uma "cultura do consumo" como forma de encontrar compradores para a capacidade de produção industrial alcançada no final da Primeira Guerra Mundial. (GORZ, 2005). Os grandes excedentes que se formam a partir desse que é considerado o primeiro conflito bélico de proporções globais demandam a constituição de uma categoria de consumidores capazes de absorver este novo volume de bens gerados em grande escala. Gorz relembra que o capitalismo clássico, que se assentava no tripé 
produção, distribuição e consumo, punha, até então, sua ênfase na produção. A ampliação em grande escala da produção requeria, porém, uma mudança de enfoque, uma vez que a produção em massa geraria estoques ampliados caso não houvesse um correspondente aumento no consumo.

É assim que o capitalismo, na visão de Gorz, passa a chamar para si a função de recriar constantemente as necessidades de consumo dos indivíduos, por meio da propaganda, do marketing e da indústria cultural. Para ele, o mercado está focado no consumidor individual e não no membro de uma sociedade ou no cidadão, o que levaria a uma inversão na lógica "produzir para consumir", que passa a se expressar como "produzir-se por meio do consumo" ". A metamorfose da cultura produtora para esta cultura do consumo se apoiaria num deslocamento da fonte de status não mais vinda da habilidade para fazer coisas, mas sim para comprá-las ou mesmo para usá-las, já que as práticas de consumo não se reduzem à compra em si dos objetos.

Baudrillard (2000) nos recorda que na sociedade de consumo existe um descolamento do valor de uso do valor de troca da mercadoria, a associação se dando exclusivamente com o aspecto simbólico, o que nos leva a uma autonomia do significado em relação ao significante. Em sua visão, a atividade de consumo implica na ativa manipulação de signos, fundamental na sociedade capitalista, que se exacerba em uma superprodução de signos e uma saturação de imagens, promovendo a estetização da realidade.

São justamente os fatores subjetivos que Bauman (2001) destaca ao apontar a crescente identificação entre felicidade e prazer atrelados ao ato da compra. A construção de um sentimento de identidade individual descansa sobre a "afirmação social" e a "aprovação social", e isto faz nascer um paradoxo central no consumo. A individualidade depende da conformidade social, a luta da personalidade individual só pode ser sustentada por meios de trocas intersubjetivas (BAUMAN, 1998: 201). Este paradoxo vai além de identificar nossa dependência sobre um estoque comum de mercadorias na construção da individualidade para estabelecer uma dependência sobre um estoque compartilhado de conhecimento.

\footnotetext{
${ }^{4}$ Gorz avança ainda na crítica ao modo de produção capitalista, quando analisa o capitalismo cognitivo, fase do modo de produção em que o capital substitui o trabalho pelo conhecimento, o qual se transforma, por sua vez, em produto imaterial, não mais se apoiando na capacidade de transformar matéria-prima para gerar bens.
} 
O alto grau de consumo em si não seria a característica da sociedade de consumo, mas sim sua desvinculação de qualquer função pragmática ou instrumental, propõe Bauman (2008). Para ele, as necessidades de satisfação de prazer através do consumo conduzem à prática de colecionar sensações. O prazer que os objetos conferem é que lhes confere legitimidade. O que impeliria a sociedade de consumo seria o desejo (desire); no capitalismo tardio, seria o capricho (wish). Ambos seriam fenômenos essencialmente evasivos e efêmeros, que prescindem de justificação. $\mathrm{O}$ desejo liga o consumo a dimensões de autoexpressão, gosto e classificação. Já o capricho, tem uma dimensão casual, espontânea e aleatória. Bauman acredita que a sociedade de consumo transforma o princípio de prazer no princípio de realidade e que a principal implicação deste fato é a subjetivação e a individualização dos riscos e contradições produzidos por instituições e pela sociedade. Com isso, os indivíduos estariam condenados a procurar soluções individuais para contradições sistêmicas.

O caráter irrestritamente individualista do consumo na atualidade também é apresentado por Colin Campbell $(2001 ; 2006)$, para quem a sociedade de consumo moderna $^{5}$ se caracteriza pela insaciabilidade dos consumidores. Como Bauman, ele também postula que no consumo existe um lugar ocupado pela emoção e pelo desejo na nossa subjetividade, que nos leva a procurar mais gratificação de desejo que satisfação de necessidades.

Enquanto Bauman vê no consumismo moderno uma fonte de desagregação social e individualização, no sentido negativo, Campbell considera que é pelo consumismo que os indivíduos conseguem resolver sua crise de identidade. Ele sugere que a atividade de comprar não é só um meio pelo qual as pessoas descobrem quem elas são, como fornece a elas a comprovação básica de sua existência. Não significa que a identidade deriva de um produto ou serviço consumido, nem que as pessoas são aquilo que consomem: ela estaria nas relações com os produtos. A característica central da cultura do consumo é que o ato de consumir vai além da mera utilidade do produto.

Além de considerar que o movimento cultural do Romantismo, no século XVIII, com o resgate do ethos individual, foi um dos ingredientes fundamentais na formação da sociedade de consumo, Campbell acredita que o consumo moderno é oriundo de uma

\footnotetext{
5 A referência moderna, em Campbell, equivale a contemporâneo, e não à época histórica da Modernidade.
} 
mudança na concepção das fontes do prazer, ou seja, na estrutura do hedonismo na subjetividade moderna.

No hedonismo tradicional, o prazer vem das sensações, se ancora nos sentidos, em uma experiência sensível, vinculada ao imediato dos sentidos humanos. Já no hedonismo moderno, Campbell defende que ocorre um deslocamento no padrão de gratificação das pessoas, que migra das sensações físicas para as emoções. A experiência passa a ser, também, imaginativa. Uma experiência imaginada, emulada, que permite a evocação de estímulos através da imaginação. Uma vez que a imaginação é sem restrições, não há limites: o controle está com o hedonista. Ele imagina, sonha acordado, tem devaneios (daydreams). Antes da posse do bem ou serviço, sua mente vagueia pela emoção, pelo prazer proporcionado por aquela fruição. Neste sentido, no hedonismo moderno os bens e serviços são detonadores de daydreams. Os consumidores não procuram satisfações de necessidades, mas o prazer das experiências autoilusivas que constroem com suas significações associadas.

A atividade fundamental do consumo seria assim a procura do prazer imaginativo a que a imagem do produto se empresta, e não a compra ou o uso dos produtos. Não à toa, desde a década de 1980, a dimensão expressiva dos produtos e serviços é a mais valorizada nos anúncios. A propaganda investe em ingredientes essencialmente românticos - o sonho, a aventura, o risco, a audácia, a amizade, o romance.

Será que isto não é feito porque na verdade os produtos não são mais "vendidos" (no sentido de impostos) mas sim "comprados" (no sentido de escolhidos) pelos consumidores? Ou seja, os anunciantes, na realidade, têm que convencer seus possíveis consumidores de que seus produtos são aqueles que melhor material dão para seus daydreams. (BARBOSA, 2010:55)

A assinatura usada pelos UCI no Rio de Janeiro para as salas premium investe nesta direção: "Permita-se viver um momento exclusivo". O convite ao consumidor traz em seu interior a noção que aquele momento já foi sonhado anteriormente, já foi imaginado. E, se imaginado, foi também desejado. Com todas as associações possíveis que o conceito de exclusividade pode aportar.

"O espírito do consumismo moderno é tudo, menos materialista" (CAMPBELL, 2001: 131), ou seja, sua motivação básica é o desejo de experimentar na realidade o que já foi desfrutado na imaginação. Há, portanto, uma antecipação do prazer já vivenciado na imaginação. Cada novo produto é visto como uma nova possibilidade de concretizar 
esta ambição. $\mathrm{O}$ autor deixa claro que o consumo não deve ser visto como uma busca desesperada pela ausência de significado, mas a solução desta busca, oferecendo, assim, significado e a identidade que todos os indivíduos buscam. Mesmo que a imaginação busque a materialização na aquisição ou uso do objeto, não é neste ato que ela encontra a sua motivação.

Com uma perspectiva semelhante, Pine e Gilmore (2001) - embora não façam diferenciações entre emoção e sensação na base dos hedonismos tradicional e moderno - abordam o tema do consumo a partir do que chamam de "economia da experiência", de onde as sensações emergem como nova fonte de valor e como uma quarta atividade econômica, para além das três atividades tradicionais: commodities, bens e serviços. Segundo os autores, a sensação tem por função encenar eventos para que sejam desfrutados por convidados. A natureza de sua atividade é da ordem do memorável.

\begin{abstract}
A atividade recentemente identificada de geração de sensações ocorre sempre que uma empresa usa intencionalmente serviços como cenário e bens como acessórios para envolver a pessoa. Enquanto as commodities são fungíveis, os bens, tangíveis, e os serviços, intangíveis, as sensações são memoráveis. Compradores de experiências - adotaremos a prática de Disney e os chamaremos de convidados - dão valor ao fato de serem envolvidos pelo que a empresa revela em um espaço de tempo. Da mesma maneira que as pessoas reduziram suas despesas com bens para gastar mais com serviços, agora eles controlam o tempo e o dinheiro que destinam aos serviços para permitirem-se sensações memoráveis - às quais atribuem um maior valor. A empresa - a chamaremos de encenadora de sensações - não apenas fornece bens ou serviços isolados, mas também a emoção resultante, cheia de sensações, que causa no cliente. (PINE e GILMORE, 2001: 23).
\end{abstract}

Em relação às práticas de ida ao cinema, notamos que a construção de cenários, a encenação e a experiência memorável, assim como a produção de daydreams (na acepção de Campbell acima comentada), não é exclusiva do caso das atuais salas prime e seus frequentadores. Como vimos, as ambientações dos palácios do cinema no Rio de Janeiro na década de 1930 já apostavam na incorporação de novos elementos associados às ideias de luxo e sofisticação, fatores até então praticamente ausentes em demais salas cariocas anteriores aos movie palaces (lanterninhas, luzes que diminuíam antes do início dos filmes, salas de espera transformadas em bares etc) e aos padrões dos cinemas Metro.

A questão é que os itens de luxo e conforto dos cinemas MGM, por exemplo, pareciam trabalhar, na época, como facilitadores da propagação ideológica do tipo de produção fílmica hoolywoodiana (filmes de um american way of life) (VIEIRA e 
PEREIRA, 1982; FERRAZ, 2009), com foco na garantia do maior número possível de público. Logo, tais itens e a ambientação MGM (com "ar condicionado perfeito") se tornaram padrões de qualidade e exemplos seguidos pelas outras empresas exibidoras no Brasil. Não parecia haver, no entanto, a busca pela diferenciação de público ou a meta de tornar o seu serviço algo exclusivo para determinados perfis de frequentadores ou classes sociais, conforme acreditamos ser a máxima dos cinemas premium de nossa recente década.

Pode estar em jogo, no caso dos cinemas de luxo que existem hoje na cidade, a potencialização da fabricação de um sonho, aliada à garantia da diferenciação do acesso ao equipamento de exibição. Provavelmente, a erotização envolvida no equipamento cinema - conforme propõe Roland Barthes no texto "Saindo do cinema" (1980), quando fala sobre a prostração das posturas dos espectadores diante da sala de cinema, "um local de disponibilidade" (BARTHES, 1980: 122) ${ }^{6}$ - conta com os fetiches de um consumo do prazer para poucos, da imaginação consensual que quer memorializar a exclusividade obtida através da participação em um paraíso de serviços e bens de luxo (talvez não importando tanto a vidência do filme).

Os resultados dos atravessamentos que os componentes desses equipamentos urbanos efetuam nos impulsos existenciais, discursivos, afetivos, sensoriais e cognitivos dos espectadores/frequentadores e nas dinâmicas e trocas urbanas é o que precisamos observar. Podemos estar diante de mais uma forma de produção dos espaços de lazer citadino voltada para a construção de paraísos onde a temática, com bases no fomento de daydreams, é o luxo e a diferenciação. Seria a franca ascensão de uma espécie de não-popularidade da sala de cinema e da potencialização da segregação socioespacial no acesso a este equipamento?

\section{Referências bibliográficas}

ALMEIDA, Paulo Sérgio e BUTCHER, Pedro. Entrevista com Marcelo Carvalho. Revista Filme B/ Edição especial Show Búzios, novembro de 2008. Disponível em: http://www.filmeb.com.br/portal/html/materia5.php.

\footnotetext{
6 "E é a disponibilidade (mais ainda que a paquera), a ociosidade dos corpos, que melhor define o erotismo moderno - não o da publicidade ou o dos streap-teases, mas o da grande cidade. É neste escuro urbano que se trabalha a liberdade do corpo; este trabalho invisível dos afetos possíveis emana de um verdadeiro casulo cinematográfico. O espectador de cinema poderia retomar a divisa do bicho-da-seda: inclusum labor illustrat, é porque estou fechado que trabalho o brilho em todo meu desejo" (BARTHES, 1980: 122).
} 
APPADURAI, Arjun. A vida social das coisas. Tradução Agatha Bacelar. Niteroi (RJ): Ed. da UFF, 2008.

ARAÚJO, Vicente de Paula. A bela época do cinema brasileiro. São Paulo: Perspectiva, 1976.

BARBOSA, Livia. A sociedade de consumo. Rio de Janeiro: Zahar Editores, 2010.

Editora FGV, 2006.

CAMPBELL, Colin (Orgs.). Cultura, consumo e identidade. Rio de Janeiro:

BARTHES, Roland. Saindo do cinema. In: BELLOUR, Raymond e outros (orgs.). Psicanálise e cinema. Tradução: Pierre André Ruprecht. São Paulo: Global, 1980.

BAUDRILLARD, Jean. O sistema dos objetos. São Paulo: Perspectiva, 2000.

BAUMAN, Zygmunt. Vida para consumo: a transformação das pessoas em mercadoria. Rio de Janeiro: Jorge Zahar, 2008.

CAIAFA, Janice. Aventura das cidades: ensaios e etnografias. Rio de Janeiro: FGV, 2007.

CAMPBELL, Colin. Eu compro, logo sei que existo: as bases metafísicas do consumo moderno. In Barbosa, Lívia \& Campbell, Colin (org). Cultura, Consumo e Identidade Rio de Janeiro: Editora FGV, 2006.

CAMPBELL, Colin. A Ética Romântica e o Espírito do Consumismo Moderno. Rio de Janeiro: Rocco, 2001.

CANCLINI, Néstor Garcia. Consumidores e cidadãos. Rio de Janeiro: Editora UFRJ, 2005.

CASTRO, Gisela Granjeiro da Silva e BUDAG, Fernanda Elouise (org.) .Comunicação e consumo: primeiros ensaios São Paulo: ESPM, 2009.

DOUGLAS, Mary e ISHERWOOD, Baron. O Mundo dos bens. Para uma antropologia do consumo. Rio de Janeiro: UFRJ, 2009.

FERRAZ, Talitha. A Segunda Cinelândia Carioca: cinemas, sociabilidade e memória na Tijuca. Rio de Janeiro: Multifoco, 2009.

GONZAGA, Alice. Palácios e Poeiras: 100 anos de cinema no Rio de Janeiro. Rio de Janeiro: Ministério da Cultura, Funarte, Record, 1996.

GORZ, André. O Imaterial: Conhecimento, Valor e Capital. Trad. Celso Azzan Jr. São Paulo: Annablume Editora, 2005.

PINE, Joe e GILMORE, Jim. Bem vindo à economia do espetáculo. In: Espetáculo dos negócios. São Paulo: Campus, 2007.

VIEIRA, João Luiz e PEREIRA, Margareth Campos da Silva. Espaços do sonho: arquitetura dos cinemas no Rio de Janeiro 1920-1950. Rio de Janeiro: Embrafilme, 1982. 